Original Research

\title{
Tribological Behaviour of Sputter Coated ZnO Thin Films
}

\author{
Ahalaptiya H Jayatissa*, Omer Ahmed, Bodhi R Manu, Adam M Schroeder
}

Mechanical, Industrial and Manufacturing Engineering (MIME) Department, The University of Toledo, Toledo, OH 43606, USA; E-Mails: ahalapitiya.jayatissa@utoledo.edu; to.omerahmed@gmai.com; bravind@rockets.utoledo.edu; adam.schroeder@utoledo.edu

* Correspondence: Ahalaptiya H Jayatissa; E-Mail: ahalapitiya.jayatitssa@utoledo.edu

Academic Editor: Ali Abdul-Aziz

Special Issue: Ceramic Matrix Composites: Performance Evaluation and Application

Recent Progress in Materials

2021, volume 3, issue 1

doi:10.21926/rpm.2101003
Received: August 13, 2020

Accepted: January 14, 2021

Published: January 22, 2021

\begin{abstract}
The tribological properties of $\mathrm{ZnO}$ thin film coated on an aluminium work piece by RF magnetron sputtering were studied as a function of deposition power, substrate coating temperature, heat treatment and rotation speed. The variation in the coefficient of friction of ZnO films produced under various levels of coating parameters and conditions were experimentally determined using a pin-on-disk tribometer. The results showed that with change in deposition conditions and heat treatment, there are significant microstructural changes in $\mathrm{ZnO}$ films, which affect the coefficient of friction. The hardness of the prepared films was also tested using a Vickers Hardness testing machine. There was a consistent and considerable decrease in the friction coefficient of the aluminium working piece after $\mathrm{ZnO}$ coating. It is found that the $\mathrm{ZnO}$ can be used as a low friction coating material for components working under oxidative and high temperature environments.
\end{abstract}

\section{Keywords}

Coefficient of friction; zinc oxide; annealing; RF magnetron sputtering

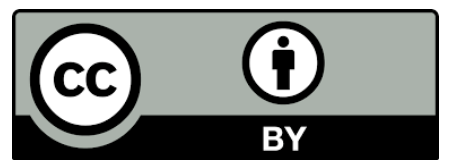

(C) 2021 by the author. This is an open access article distributed under the conditions of the Creative Commons by Attribution License, which permits unrestricted use, distribution, and reproduction in any medium or format, provided the original work is correctly cited. 


\section{Nomenclature}

$\begin{array}{llll}\text { AFM } & \text { Atomic force microscopy } & \mathrm{MoS}_{2} & \text { Molybdenum disulfide } \\ \text { ALD } & \text { Atomic layer deposition } & \text { PLD } & \text { Pulsed laser deposition } \\ \text { COF } & \text { Coefficient of friction } & \text { RF } & \text { Radio frequency } \\ \text { CBN } & \text { Cubic boron nitride } & \mathrm{rpm} & \text { Rotations per minutes } \\ \text { DLC } & \text { Diamond-like carbon } & \mathrm{SEM} & \text { Scanning electron microscopy } \\ p_{\max } & \text { Hertzian contact pressure } & \mathrm{WS}_{2} & \text { Tungsten disulfide } \\ \mu_{\mathrm{k}} & \text { kinetic friction coefficient } & \mathrm{XRD} & \text { X-rad diffraction } \\ \text { MEMS } & \text { Micro-Electro-Mechanical system } & \mathrm{ZnO} & \text { Zinc oxide }\end{array}$

\section{Introduction}

Surface coatings are an effective alternative to liquid lubricants to improve the performance of materials in aggressive environments. Tribological applications require stable and durable coatings that function as lubricants and prevent surface damage. Thin films are usually used in tribology applications to improve the coefficient of friction, wear resistance and for aesthetic purposes. Some of the well-known solid lubricants include $\mathrm{MoS}_{2}$, cubic boron nitride (c-BN), diamond-like carbon (DLC), and graphene. However, a single solid film lubricant that could be used at various levels of humidity, temperature and pressure cannot be identified due to the complexity of the mechanisms that give these materials their lubricating properties. For instance, graphene is a good lubricant under high humidity conditions, whereas $\mathrm{MoS}_{2}$ and DLC cannot be used as the solid lubricants in the presence of atmospheric moisture [1-3].

Transition metal sulfides such as $\mathrm{MoS}_{2}$ and $\mathrm{WS}_{2}$ are some of the highly investigated solid lubricants due to their layered crystal structures. However, its lubricating properties deteriorate under high humidity and high temperature conditions. In order to address this drawback of metal sulfide-based lubricants, metal oxide films have been investigated for tribological purposes. Among them, $\mathrm{ZnO}$ attracted much attention because of its high stability at elevated temperatures and in reactive environments. $\mathrm{ZnO}$ thin films have found widespread applications in MEMS, electronics and mechanical coatings because of its properties such as low thermal expansion, high melting temperature and thermal capacity [4-7]. ZnO is an environmentally benign and well abandon material. Also, $\mathrm{ZnO}$ can be used in bioengineering applications such as bone and joint replacements and tissue culture. The high heat capacity and heat conductivity, low thermal expansion and high melting temperature of $\mathrm{ZnO}$ are beneficial for the above applications. Tribological and mechanical properties of the $\mathrm{ZnO}$ thin films have been investigated in the past to enhance the operating life of devices. Chai, Liu et al. [8, 9] studied the ZnO layer deposited by atomic layer deposition (ALD) for different crystal structures and have found the coefficient of friction to be in the range of 0.08-0.12. The low friction coefficient of ALD-deposited ZnO films was due to its smaller crystal size and deposition temperature. S.V. Prasad et al. conducted experiments at room temperature using a pulsed laser deposition (PLD) process. It was found that the friction coefficient was in the range of 0.1-0.16 [10] when the coating was done in the presence of oxygen $[10,11]$. However, the 
coefficient of friction was higher when the coating was done in vacuum (0.34). The steady state coefficient of friction for PLD ZnO ranged from 0.16-0.34 [11]. In another study reported by Zabinski et al. [12], the coefficient of friction of hot-pressed $\mathrm{ZnO}$ was 0.65 , relatively high compared to the other reported values.

It was evident from the literature review that the coefficient of friction depends on deposition technique, temperature and atmosphere. However, tribological studies on $\mathrm{ZnO}$ films deposited by an RF Magnetron Sputtering technique has been rarely undertaken. In this study, ZnO films coated by a reactive RF magnetron sputtering technique on an aluminium substrate were investigated. The friction coefficient was calculated using a pin-on-disc tribometer arrangement using steel pins. The variation of the coefficient of friction as a function of the sputtering parameters, such as deposition power and substrate temperature, was determined for the ZnO film. The effects of the sputtering parameters and the heat treatment on the microstructure and hardness were also investigated using electron microscopy, X-ray diffraction analysis and Vickers hardness tests. It was found that the tribological properties of $\mathrm{ZnO}$ can be modified by changing the processing conditions.

\section{Experimental Procedure}

ZnO thin films were developed on the aluminum substrates by an RF (13.56 MHz) radio frequency magnetron sputtering. In this research, the zinc target (99.9\% zinc) was bombarded with positive argon ions $[13,14]$, which displaced the zinc atoms. The argon/oxygen ratio was controlled at 1:1 to influence the chemical composition of the finished $\mathrm{ZnO}$ film. A pressure of $125 \mathrm{mTorr}\left(24 \times 10^{-4}\right.$ psi) was created using a multi-stage vacuum pump.

The $\mathrm{ZnO}$ coatings were done at three different combinations of RF power, coating time and substrate temperature. The first set of coatings were done at $250 \mathrm{~W}$ for $90 \mathrm{~min}$. and the second set at $300 \mathrm{~W}$ for $60 \mathrm{~min}$. The third set of coatings were deposited while heating the aluminum substrate to $100{ }^{\circ} \mathrm{C}$ during the deposition of $\mathrm{ZnO}$ at $250 \mathrm{~W}$ for $90 \mathrm{~min}$.

The coefficient of friction was measured using a pin-on-disc tribometer. The frictional force exerted on the surface of the sample was measured by the deflection of a stationary pin. The coated substrate was mounted on the chuck and rotated at a constant speed using a DC motor. The pin was placed on the surface of the disk so that it touched the sample's surface. The deflection in the counter face pin was measured using a set of strain gauges. A detailed description of this instrument can be found elsewhere $[15,16]$. The pin was made of steel (SS 301) rod with a diameter of $6 \mathrm{~mm}$. The radius of curvature of contact region was $0.5 \mathrm{~mm}$ and the surface roughness of the pin was 110 $\pm 10 \mathrm{~nm}$. A normal force was exerted on the pin due to its own weight and external application of normal force. Extra weights were used to change the normal force during different experimental runs. A data acquisition system interfaced with a computer was used to acquire the strain gauge data. $\mathrm{ZnO}$ was coated on the aluminum alloy 1100 as it is commonly used in general fabrication and metal spinning. Aluminum alloy 1100 has a composition of $99.88 \% \mathrm{Al}, 0.1 \% \mathrm{Cu}$ and $0.02 \%$ other. Prior to deposition, the substrates were cut into appropriate dimensions $(8 \mathrm{~cm} \times 8 \mathrm{~cm}$, thickness 0.8 $\mathrm{mm}$ ) and polished to remove any surface cracks. It was then cleaned with soap, water, and isopropyl alcohol to remove grease and dirt. Finally, the substrates were then sonicated in a mixture of acetone, isopropanol alcohol and distilled water for removing surface contaminations.

The pin-on-disc tribometer tests were conducted on annealed and unannealed samples. The samples were annealed to understand the effect of surface hardness on the coefficient of friction. 
During annealing, the ductility of the material increases, and the surface hardness decreases. Hence, the friction coefficient of the annealed samples should be greater than unannealed samples. Annealing was done on one of every set of the above samples at $400{ }^{\circ} \mathrm{C}$ for $1 \mathrm{hr}$.

The X-ray diffraction (XRD) analysis was accomplished with a $\mathrm{Cu} K \alpha\left(\lambda=1.5418 \mathrm{~A}^{\circ}\right)$ radiation (PANalytical $X^{\prime}$ Pert Pro MPD) to determine the crystal structure of both the Al substrate and $\mathrm{ZnO}$ films. The scan range was maintained from $20^{\circ} \mathrm{C}$ to $70{ }^{\circ} \mathrm{C}$. The surface roughness of thin films was estimated with atomic force spectroscopy (AFM) measurements.

\section{Results and Discussion}

\subsection{Structural Properties}

Figure 1 shows the XRD results of the Al substrate with and without annealing. According to JCPDS 01-1176, both substrates displayed clear peaks corresponding to (111), (200) and (220) planes of Al. However, several low-intensity $\mathrm{Al}_{2} \mathrm{O}_{3}$ peaks could be observed from both spectra shown. This is due to the naturally-formed protective ultra-thin $\mathrm{Al}_{2} \mathrm{O}_{3}$ layer on the substrate surface before the experiments. This layer prevented further oxidation of the inner part, even at $400{ }^{\circ} \mathrm{C}$. In addition, after the heat treatment the (200) showed a higher intensity relative to the other peaks, which indicated a possible preferential growth at (200) direction (not shown in XRD).

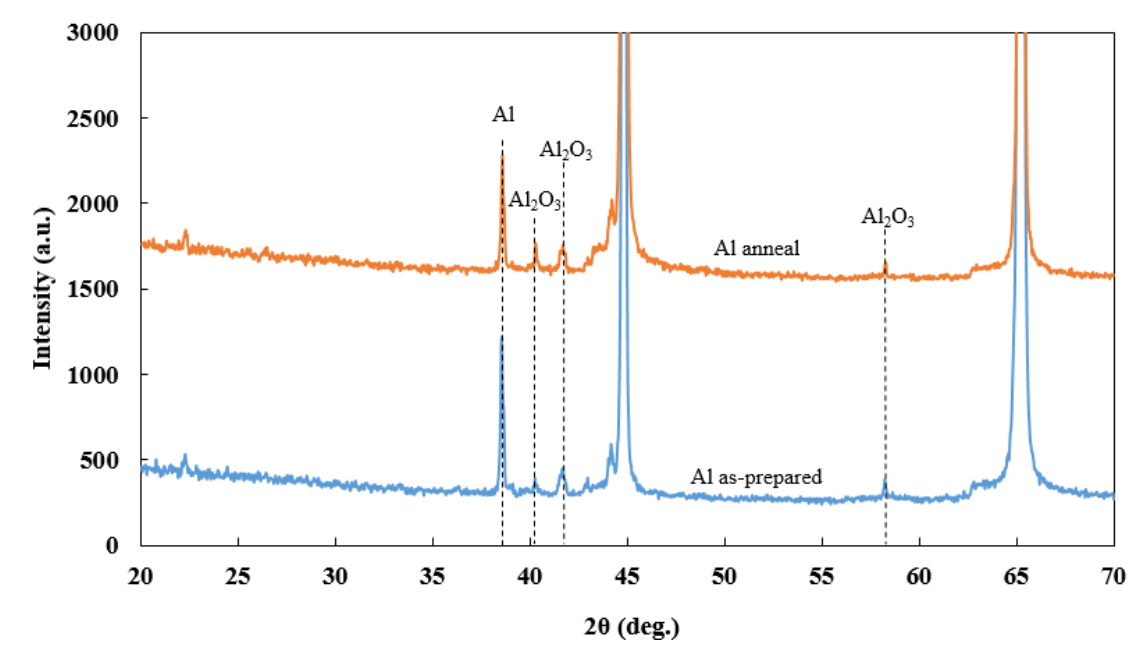

Figure 1 The XRD results of the as-prepared and annealed Al substrates.

Figure 2 displays the XRD results of $\mathrm{ZnO}$ coated Al substrates before and after annealing at $400{ }^{\circ} \mathrm{C}$. The XRD patterns show peaks corresponding to polycrystalline ZnO films. By comparing these peaks' positions with JCPDS 01-075-0576, the peaks corresponding to (100), (002) and (101) planes from $30^{\circ}$ to $40^{\circ}$ were identified and labelled in Figure 2. A preferential growth of $\mathrm{ZnO}$ along the (002) plane could be observed. Also, the annealed ZnO/Al sample showed an overall higher peak intensity, indicating that the annealing process enhanced the degree of crystallinity of the ZnO film. 


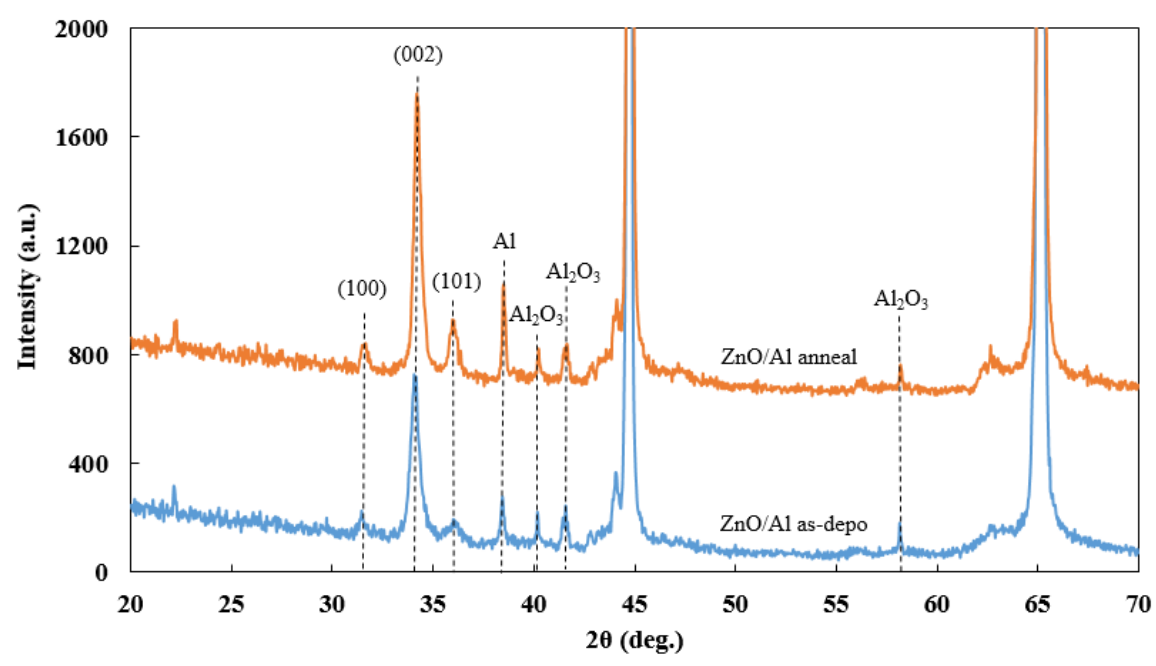

Figure 2 XRD results of the as-deposited and annealed $\mathrm{ZnO} / \mathrm{Al}$ samples.

Figure 3 shows the SEM images of the Al substrate, the as-deposited ZnO layer on the Al, and the annealed $\mathrm{ZnO}$ layer on the Al substrate. The film surfaces roughness of coated films was studied with atomic microscope (AFM). The Al substrate has directional scratches of a few hundred nanometers (average roughness $120 \mathrm{~nm}$ (scanned area is $1 \mu \mathrm{m}^{2}$ ), which were created during the polishing process. After the coating of the $\mathrm{ZnO}$ using the sputtering method, the film surface became smoother as shown in Figure 3(b). In order to find more information about the as-deposited $\mathrm{ZnO}$ layer, a higher resolution of the as-deposited film is shown in Figure 3(d), and several subnanometer-size $\mathrm{ZnO}$ grains can be clearly seen on the surface. When the film was annealed, the grain size increased due to crystal growth from the thermal diffusion process as shown in Figure 3(c).
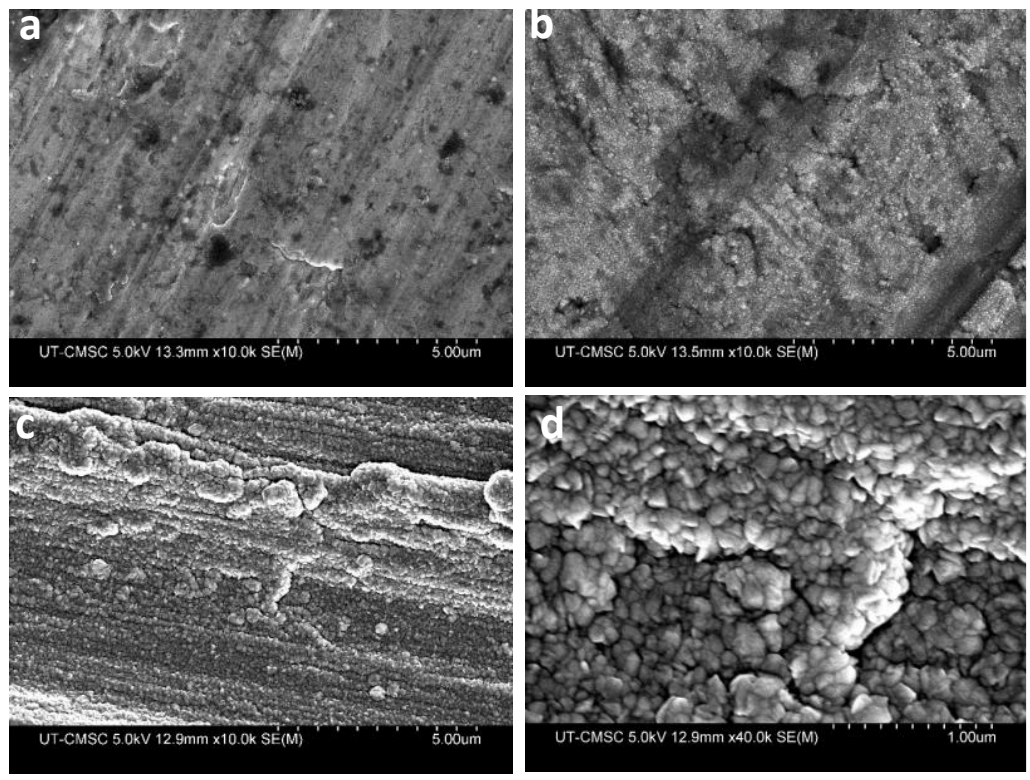

Figure 3 SEM images of the Al substrate (a), as-deposited ZnO layer on Al (b), annealed ZnO layer (c), and high-resolution SEM image of the as-deposited ZnO Al substrate (d). Images compare surfaces after and before coating of $\mathrm{ZnO}$ thin films. The figure (d) shows the size of $\mathrm{ZnO}$ crystallites produced on the surface. 


\subsection{Hardness}

Table 1 summarizes the Vickers hardness of the as-deposited annealed $\mathrm{ZnO}$ film and the aluminium substrate. The thickness of these $\mathrm{ZnO}$ films was $300 \pm 10 \mathrm{~nm}$ with a uniform coating because the substrates were rotated during the coating process. These results are in reasonable agreement with previously reported data for both $\mathrm{ZnO}$ [17] and aluminium [18]. Also, ZnO films obtained by this method is very transparent as observed in the optical images of coatings shown in Figure 7. No significant difference in the hardness of the as-deposited zinc oxide film and substrate was observed. All the variations of the $\mathrm{ZnO}$ coatings before annealing indicated similar Vickers hardness values (approximately $20 \mathrm{MPa}$ ). Due to a small change in hardness values in ZnO films made at different rf power levels, it is difficult to make exact correlation between the tribology properties and Vickers hardness of films. However, after annealing, a noticeable difference in hardness was observed because annealing decreases the hardness of the aluminium substrate and $\mathrm{ZnO}$ coating. This decrease in hardness increased the ductility of the $\mathrm{ZnO}$ film which caused it to wear faster.

Table 1 Vickers hardness of substrate and ZnO film coated samples before and after thermal annealing, in MPa (Measurement error $\pm 0.05 \mathrm{MPa}$ ).

\begin{tabular}{lll}
\hline & As-deposited & Annealed \\
\hline As-received Aluminum & 40.1 & 32.9 \\
$\mathrm{ZnO}(250 \mathrm{~W})$ & 19.6 & 15.2 \\
$\mathrm{ZnO}(300 \mathrm{~W})$ & 19.8 & 18.5 \\
$\mathrm{ZnO}(250 \mathrm{~W})$ deposited @ $100^{\circ} \mathrm{C}$ & 19.8 & - \\
\hline
\end{tabular}

\subsection{Coefficient of Friction}

The coefficient of friction for the different parameters and variations of the $\mathrm{ZnO}$ coatings was compared. The friction coefficient $\left(\mu_{k}\right)$ was calculated for steady state kinetic friction. Frictional force measurements were calculated using constant speeds of $100 \mathrm{rpm}$ and $150 \mathrm{rpm}$ and with a constant normal load of $0.25 \mathrm{~N}$. Maximum Hertzian contact pressure $\left(p_{\max }\right)$ of bulk materials has been calculated using the contact pressure eq. (1) $[19,20]$.

$$
P_{\text {max }}=\left\{\frac{3 P}{2 \pi a^{2}}\right\}
$$

Here, $P$ is applied normal load and $a$ is the contact radius. Due to the normal load of $0.25 \mathrm{~N}$, Hertzian contact pressure is exerted on the interacting materials, which was calculated to be 262 MPa (maximum Hertzian contact pressure). The experiments were conducted at ambient room temperature and pressure. However, this calculation can be employed as an approximation because the maximum Hertzian contact pressure of thin film coated on different materials are very different from bulk materials [21]. 
Table 2 represents the average of 10,000 data points of coefficient of friction (COF) measured during steady state conditions. The tribology tests were conducted multiple times on identical samples to ensure repeatability. It was noticed that the COF value increased when the speed was increased. This increase in COF with speed was due to obstruction caused by the debris particles of the $\mathrm{ZnO}$ layers scratched from the surface of the film. When the $\mathrm{ZnO}$ films were subjected to higher speeds under the same load, these layers deteriorated at a faster pace. These dislocated film particles caused an obstruction in the path of the counter face stainless steel pin. Thus, there is an increase in the COF at higher speeds. This trend was consistently observed in all variations of the zinc oxide coatings.

Table 2 Average of 10,000 data points of COF of various ZnO films for two different speeds.

\begin{tabular}{lll}
\hline Layer/Type of surface & $\mathbf{1 0 0} \mathbf{~ r p m}$ & $\mathbf{1 5 0} \mathbf{~ r p m}$ \\
\hline As-received Aluminium & 0.60 & 0.84 \\
ZnO (250 W, $90 \mathrm{~min})$ & 0.14 & 0.17 \\
ZnO (250 W, $\left.90 \mathrm{~min}, 100^{\circ} \mathrm{C}\right)$ & 0.19 & - \\
ZnO (300 W, $60 \mathrm{~min})$ & 0.28 & 0.38 \\
As-received Al annealed & 0.87 & 0.85 \\
ZnO (250 W) annealed & 0.21 & 0.22 \\
ZnO (300 W) annealed & 0.34 & 0.37 \\
\hline
\end{tabular}

However, compared to unannealed samples, annealed samples showed a smaller increase in the coefficient of friction at an increased speed. This is because annealing increases the ductility of the film at the expense of hardness. This increase in ductility increases the friction coefficient but decreases wear. Hence, wear debris that assisted in an increase of friction was not formed easily due to the increase in ductility. The annealing process increased the coefficient of friction, but it also proved helpful at higher speeds as it reduced the formation of wear debris. Therefore, annealing proved to be a good alternative for higher speed applications.

Figure 4 shows a comprehensive view of the effect of the coating parameters on the tribological properties of $\mathrm{ZnO}$ films on an aluminum substrate. The COF of the base material (as-received aluminum) was compared with the coatings prepared at different combinations of RF power, coating time, and substrate. The first set of substrates, (a) in Figure 4, was coated with $250 \mathrm{~W}$ RF power for $90 \mathrm{~min}$ inside a vacuum chamber with an argon/oxygen ratio of 1:1. The second set of substrates, (b), was heated to $100{ }^{\circ} \mathrm{C}$ for deposition of the $\mathrm{ZnO}$ film with $250 \mathrm{~W}$ RF power for 90 min inside a vacuum chamber with a similar Argon/Oxygen concentration. The third set of ZnO coatings, (c), was obtained with an RF power of $300 \mathrm{~W}$ and a deposition time of $60 \mathrm{~min}$.

There was a consistent significant decrease in the average COF of the substrates after the $\mathrm{ZnO}$ coatings were deposited, compared with the as-received aluminum substrate. The as-received aluminum had an average COF of 0.6; after $\mathrm{ZnO}$ deposition the COF drastically decreased to 0.17 (RF $250 \mathrm{~W}$ ), 0.19 (RF $250 \mathrm{~W}$, heated) and 0.37 (RF $300 \mathrm{~W}$ ). The behaviour of the friction coefficient of the ZnO $250 \mathrm{~W}$ film was found to be irregular, ranging from 0.12 to 0.25 . However, when the 
substrate was heated to $100{ }^{\circ} \mathrm{C}$ during the deposition, the fluctuation in the coefficient of friction decreased and a steady value of 0.2 was observed throughout the entire test cycle.

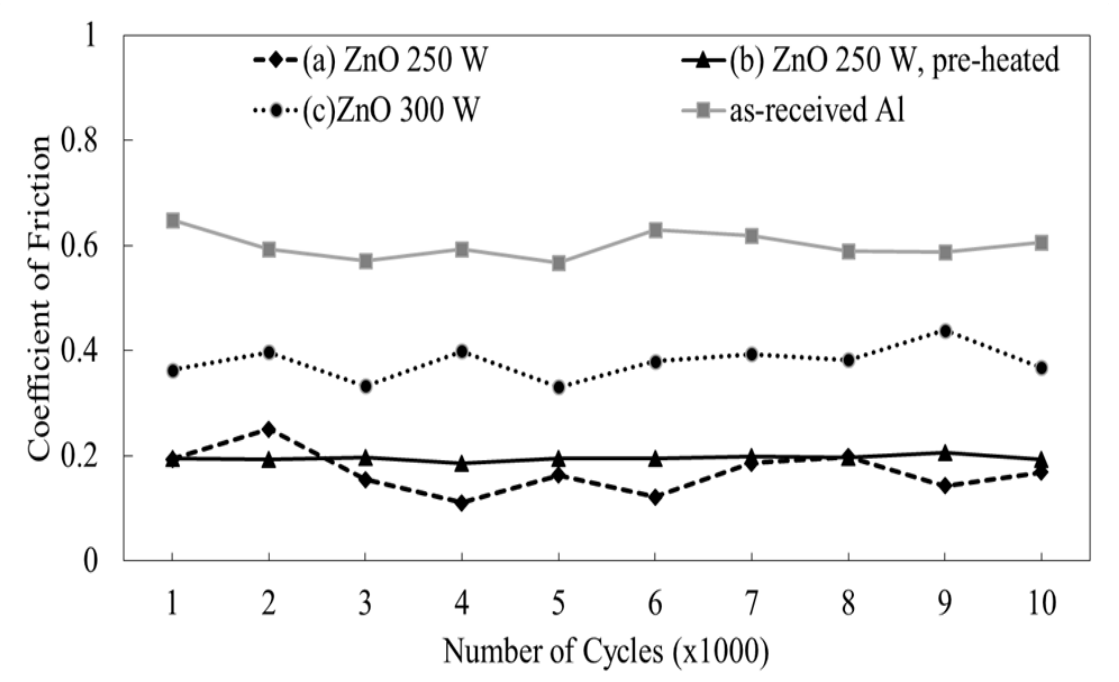

Figure 4 The coefficient of friction for the ZnO coatings at $150 \mathrm{rpm}$; (a) ZnO deposited at $250 \mathrm{~W}$, (b) ZnO deposited at $250 \mathrm{~W}$, pre-heated, (c) ZnO deposited at $300 \mathrm{~W}$ coatings and the as-received aluminium without a coating. (Standard deviation of data for (a), (b), (c) and (d) are 0.044, 0.0063, 0.025, and 0.038, respectively).

As represented in Figure 4, the friction coefficient depends on the RF power, coating time and substrate conditions. The coefficient of friction increased with an increase in the coating power from 250 to $300 \mathrm{~W}$. Han et al. conducted a surface morphological analysis of sputtered ZnO films at various sputtering power ranging from 90 to $140 \mathrm{~W}$. It was concluded that as the sputtering power is increased, the grains begin to grow loosely, and the thin film will have a rugged and irregular structure [22]. Also, with an increase in sputtering power, an oriented crystallographic growth of ZnO film occurred along the (002) plane with the $\mathrm{c}$ axis perpendicular to the aluminum substrate. This increased the surface roughness of the deposited film [23]. For this study, the surface roughness of the film produced at $300 \mathrm{~W}$ was higher than the one produced at $250 \mathrm{~W}$, thus increasing the coefficient of friction with sputtering power.

As stated earlier, when the coating was done at a substrate temperature of $100^{\circ} \mathrm{C}$, the fluctuation in the coefficient of friction with the number of cycles decreased. However, no apparent change in the mean friction coefficient was observed compared with the coating at room temperature. Increasing the substrate temperature while sputtering increases the deposition rate, grain size and oxygen concentration on the film. However, this increase was dominant only at substrate temperatures above $250{ }^{\circ} \mathrm{C}[12,24,25]$. Since the substrate temperature was kept at $100{ }^{\circ} \mathrm{C}$, there was no dominant change on the microstructure to affect the friction coefficient. However, substrate heating could reduce the biaxial stress generated on the film and therefore the friction coefficient did not fluctuate with time for this experiment [26].

Figure 5 shows the annealing effect on $\mathrm{COF}$ of $\mathrm{ZnO}$, as well as on the Al substrates. The annealing reduces the number of dislocations that lead to the change in ductility and hardness. After annealing the $\mathrm{ZnO}$ coated substrates, the hardness decreased which had a direct effect on the COF. Annealing increased the COF and ductility with a decrease in hardness. This behaviour and an increase in the 
COF after annealing was noticeable in Figure 4. For the $250 \mathrm{~W}$ coatings, the average COF increased from 0.17 before annealing to 0.22 after annealing. At the time of deposition of the thin film, the ZnO grains on the surface were not formed homogeneously, which provided a consistent layer of reduced friction due to a smaller grain size. The increase in the COF after annealing is also apparent in the as-received aluminum substrates as the average COF increased from 0.6 (as-received) to 0.866 after annealing at $400^{\circ} \mathrm{C}$.

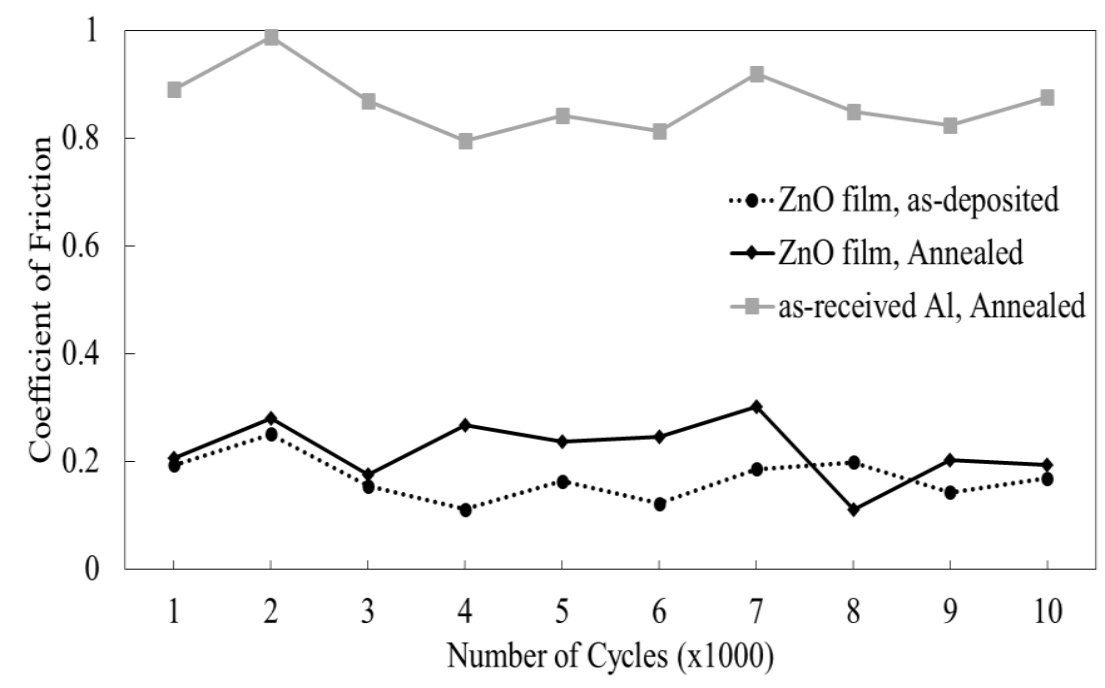

Figure 5 The coefficient of friction for the $\mathrm{ZnO}$ coatings at $150 \mathrm{rpm}$ and the as-received aluminum annealed. (Standard deviation of as-deposited $\mathrm{ZnO}$ film, annealed $\mathrm{ZnO}$ and as-received $\mathrm{Al}$ are $0.042,0.056$ and 0.055 , respectively).

Investigations on the effect of coating pressure and annealing on the microstructure of the $\mathrm{ZnO}$ film have been conducted in the past $[26,27]$. Hiramatsu et. al conducted experiments on the effect of coating pressure on the microstructure of the $\mathrm{ZnO}$ film after annealing. It was found that the change in biaxial stress due to annealing is less for $\mathrm{ZnO}$ film produced at a coating pressure greater than $7 \mathrm{~Pa}$. The sputtering pressure for this study was $16 \mathrm{~Pa}$, and at this pressure the change in biaxial stress due to annealing is greater for aluminum than the $\mathrm{ZnO}$ film. This gives a possible explanation for why the observed increase in the friction coefficient was greater for the aluminum substrate than the $\mathrm{ZnO}$. The average COF increased from 0.6 to 0.866 in the case of aluminum but for $\mathrm{ZnO}$ this increase was only from 0.17 to 0.22 .

Figure 6 shows the variation of the COF with time for a $\mathrm{ZnO}$ thin film deposited at room temperature $\left(28^{\circ} \mathrm{C}\right)$ and at a power of $250 \mathrm{~W}$. This test was conducted at $150 \mathrm{rpm}$ under a load of $0.25 \mathrm{~N}$. Although at initial stages the COF is slightly high, it decreased after $4 \mathrm{~min}$. Sputtered ZnO films have preferential growth along the (002) direction (perpendicular to the substrate) $[16,23]$. Because of this preferential growth, the average roughness of the as-deposited film is higher, and this leads to an increase in the coefficient of friction for the as-deposited film. With an increase in cycle time, this preferentially grown $\mathrm{ZnO}$ will be worn off, thereby reducing the roughness and the friction coefficient. The average steady state COF of the $\mathrm{ZnO}$ film in long term use was found to be 0.19. During the testing of the $\mathrm{ZnO}$ film for $25 \mathrm{~min}$, the COF value remained in the same range with low variations and steady lubricity. Though this test run is not enough to fully understand the 
dynamic performance of $\mathrm{ZnO}$, this data indicated that $\mathrm{ZnO}$ can be a very useful coating material for moving components of mechanical systems.

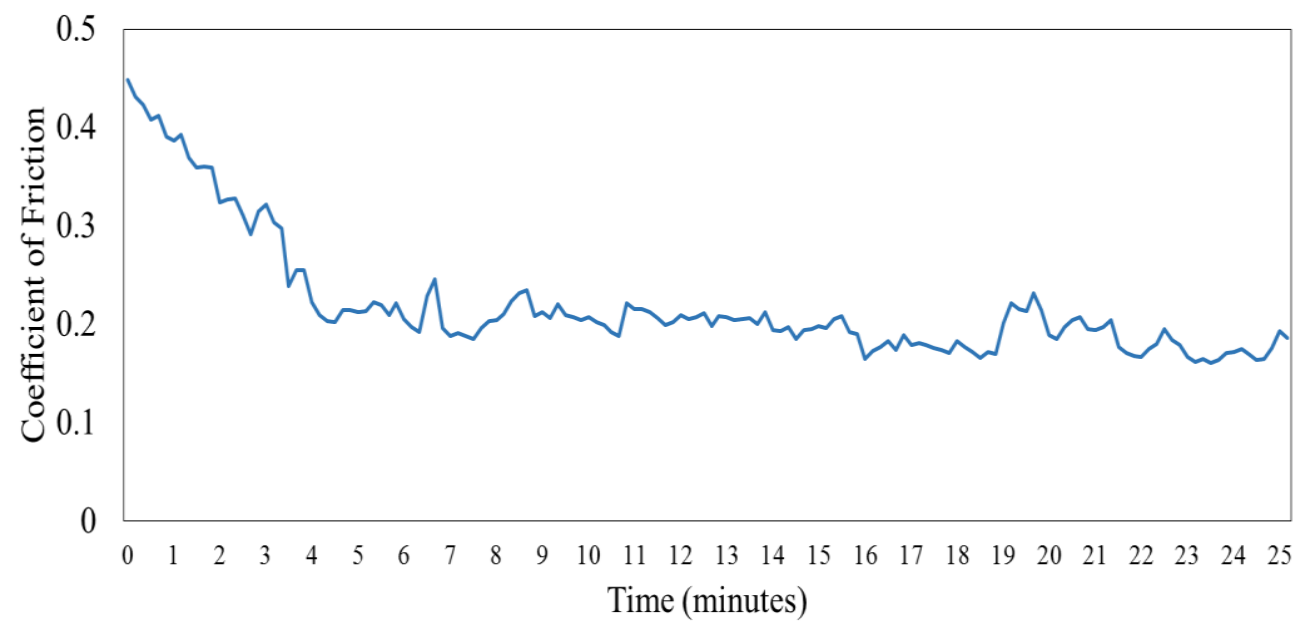

Figure 6 The long-term friction performance of a $\mathrm{ZnO}$ thin film. The $\mathrm{ZnO}$ thin film was deposited at room temperature $\left(28^{\circ} \mathrm{C}\right)$ and at a power of $250 \mathrm{~W}$. The test was conducted at $150 \mathrm{rpm}$ under a load of $0.25 \mathrm{~N}$. (Standard deviation of whole data shown above is 0.072 and standard deviation for data in $6-25 \mathrm{~min}$ is 0.02 ).

The difference in tribological performance and the COF of annealed and as-deposited coatings can be explained by observing the wear tracks after the tribology tests. Figure 7 shows the difference in the wear tracks between the as-deposited and annealed ZnO coatings. The asdeposited $\mathrm{ZnO}$ coatings showed a very low COF of 0.17 , whereas the similarly deposited and annealed ZnO substrates had a COF of 0.22. In Figure 7(a) the width of the wear track is narrower compared to Figure $7(\mathrm{~b})$. The increase in the width of the wear track is due to the decreased hardness after annealing. We believe that the wear happens because delamination of the ZnO layer due to mechanical vibration of coated layer on the substrate. When the film is heated (annealed), there is more possibilities towards delamination of $\mathrm{ZnO}$ from the substrate due to the variation of thermal expansion of two materials.
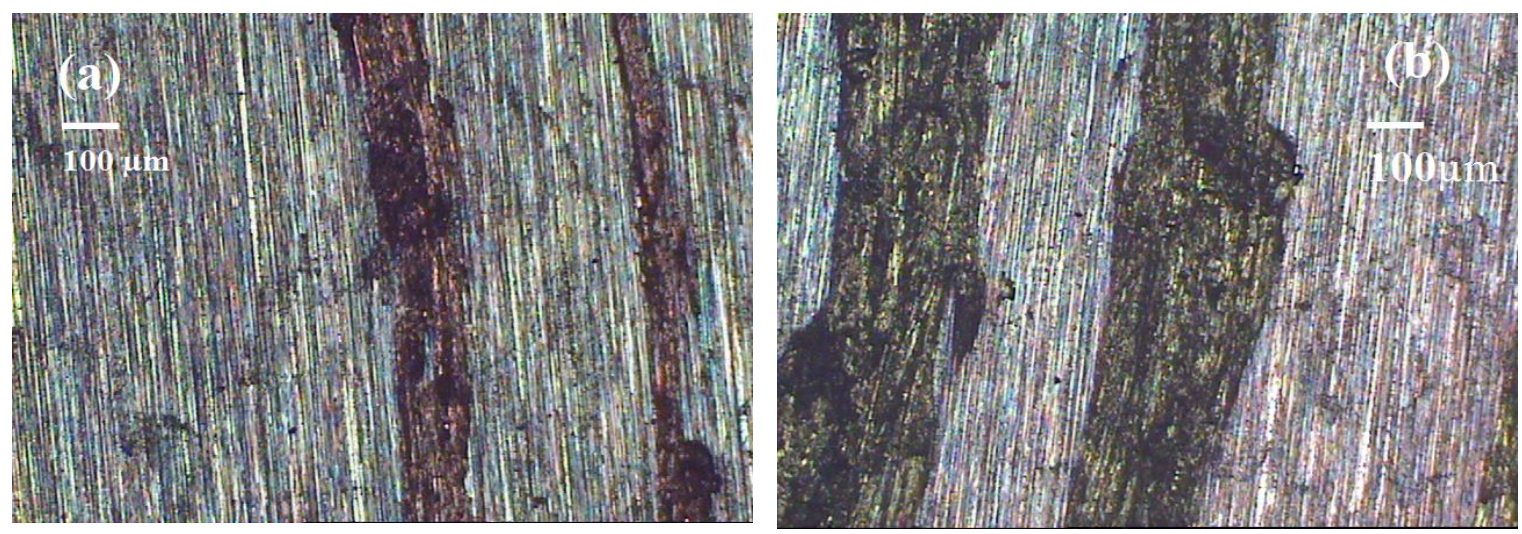

Figure 7 The surface morphology of the ZnO film coated with $250 \mathrm{~W}$ power on (a) the as-received aluminum and (b) after annealing. The annealed substrate has a wider wear 
track than the as-received aluminium substrate indicating that the substrate preparation also plays a significant effect on wear characteristics of $\mathrm{ZnO}$ films.

\section{Conclusion}

This paper reposts the dependence of tribological properties of $\mathrm{ZnO}$ thin films as a function of deposition conditions and post-thermal annealing.

- ZnO films prepared by RF magnetron sputtering with different deposition powers and durations were investigated to understand their tribological behaviour.

- The effect of annealing on the microstructure, hardness, and coefficient of friction was also studied. It was found that low power deposition over a longer period is preferable for better tribological performance. Post-annealing process influences the wear characteristics of ZnO films due to the weakening of the interface between $\mathrm{ZnO}$ and substrate.

- The annealed ZnO films produced a higher COF but they performed comparatively better at high rotation speeds.

- Although the COF of $\mathrm{ZnO}$ coatings deposited by RF magnetron sputtering were found to be low, they were still higher than other deposition techniques such as atomic layer deposition (ALD) and pulsed laser deposition (PLD).

- Finally, sputtering proves to be more effective in decreasing the COF than thermal evaporation, sol-gel and hot-pressing deposition techniques.

Currently, we are investigating the possibility to use $\mathrm{ZnO}$ coating in an additive manufacturing process.

\section{Acknowledgements}

This work was partially supported by a grant (CMMI 0855769) from National Science Foundation (NSF) of USA.

\section{Author Contributions}

A. H. Jayatissa worked on research designing, data analysis and manuscript preparation, $O$. Ahmad and B. R. Manu contributed to data collection and analysis, and A. M. Schroeder worked on proofreading the final paper.

\section{Funding}

This work was partially supported by a grant (CMMI 0855769) from National Science Foundation (NSF) of USA.

\section{Competing Interests}

The authors have declared that no competing interests exist.

\section{References}

1. Berman D, Erdemir A, Sumant AV. Few layer graphene to reduce wear and friction on sliding steel surfaces. Carbon. 2013; 54: 454-459. 
2. Berman D, Erdemir A, Sumant AV. Graphene: A new emerging lubricant. Mater Today. 2014; 17: 31-42.

3. Furlan KP, de Mello JD, Klein AN. Self-lubricating composites containing $\mathrm{MoS}_{2}$ : A review. Tribol Int. 2018; 120: 280-298.

4. Battez AH, González R, Viesca JL, Fernández JE, Fernández JD, Machado A, et al. CuO, $\mathrm{ZrO}_{2}$ and ZnO nanoparticles as antiwear additive in oil lubricants. Wear. 2008; 265: 422-428.

5. Mezher M, Garris R, Mansfield LM, Horsley K, Weinhardt L, Duncan DA, et al. Electronic structure of the $\mathrm{Zn}(\mathrm{O}, \mathrm{S}) / \mathrm{Cu}$ (In, Ga) Se $\mathrm{S}_{2}$ thin-film solar cell interface. Prog Photovolt. 2016; 24: 1142-1148.

6. Vanaraja M, Muthukrishnan K, Boomadevi S, Karn RK, Singh V, Singh PK, et al. Dip coated nanostructured $\mathrm{ZnO}$ thin film: Synthesis and application. Ceram Int. 2016; 42: 4413-4420.

7. Wang $M H, M a X Y$, Jiang $W$, Zhou F. Synthesis of doped ZnO nanopowders in alcohol-water solvent for varistors applications. Mater Lett. 2014; 121: 149-151.

8. Chai Z, Liu Y, Lu X, He D. Influence of crystal structure on friction coefficient of ZnO films prepared by atomic layer deposition. Sci China Technol Sci. 2016; 59: 506-512.

9. Chai Z, Lu X, He D. Atomic layer deposition of zinc oxide films: Effects of nanocrystalline characteristics on tribological performance. Surf Coat Technol. 2012; 207: 361-366.

10. Prasad SV, Zabinski JS. Tribological behavior of nanocrystalline zinc oxide films. Wear. 1997; 203-204: 498-506.

11. Prasad SV, Walck SD, Zabinski JS. Microstructural evolution in lubricious ZnO films grown by pulsed laser deposition. Thin solid films. 2000; 360: 107-117.

12. Zabinski JS, Corneille J, Prasad SV, Mc Devitt NT, Bultman JB. Lubricious zinc oxide films: Synthesis, characterization and tribological behaviour. J Mater Sci. 1997; 32: 5313-5319.

13. Madou MJ. Fundamentals of microfabrication: The science of miniaturization. Boca Raton: CRC press; 2002.

14. Maurya DK, Sardarinejad A, Alameh K. Recent developments in RF magnetron sputtered thin films for pH sensing applications-an overview. Coatings. 2014; 4: 756-771.

15. Ahmed O, Jayatissa AH. Tribological properties of multilayer TiN and $\mathrm{MoS}_{2}$ thin films. Colloid Surf Sci. 2017; 2: 137-142.

16. Jayatissa AH, Manu BR. Tribological Properties at the Interface of the aluminum and aluminum oxide. J Multidiscip Engg Stud. 2019; 5: 2594-2599.

17. Yoshimura HN, Molisani AL, Narita NE, Manholetti JL, Cavenaghi JM. Mechanical properties and microstructure of zinc oxide varistor ceramics. Mater Sci Forum. 2006; 530: 408-413.

18. Tiryakioğlu M, Robinson JS, Salazar-Guapuriche MA, Zhao YY, Eason PD. Hardness-strength relationships in the aluminum alloy 7010. Mater Sci Eng A. 2015; 631: 196-200.

19. Budynas RG, Nisbett JK. Shigley's mechanical engineering design. New York: McGraw-Hill; 2008.

20. Manu BR, Jayatissa AH. Effect of humidity on friction of molybdenum disulfide films produced by thermal evaporation on titanium substrates. Chem Sci Int J. 2020; 29: 25-33.

21. Johnston GJ, Wayte R, Spikes HA. The measurement and study of very thin lubricant films in concentrated contacts. Tribol Trans. 1991; 34: 187-194.

22. Han D, Wang $Y$, Zhang S, Sun L, Han R, Matsumoto S, et al. Influence of sputtering power on properties of $\mathrm{ZnO}$ thin films fabricated by RF sputtering in room temperature. Sci China Inf Sci. 2012; 55: 951-955. 
23. Lu YM, Hwang WS, Liu WY, Yang JS. Effect of RF power on optical and electrical properties of ZnO thin film by magnetron sputtering. Mater Chem Phys. 2001; 72: 269-272.

24. Chaabouni F, Abaab M, Rezig B. Effect of the substrate temperature on the properties of ZnO films grown by RF magnetron sputtering. Mater Sci Eng B. 2004; 109: 236-240.

25. Ghorannevis Z, Hosseinnejad MT, Habibi M, Golmahdi P. Effect of substrate temperature on structural, morphological and optical properties of deposited Al/ZnO films. J Theor Appl Phys. 2015; 9: 33-38.

26. Hiramatsu $T$, Furuta $M$, Furuta $H$, Matsuda $T$, Hirao $T$. Influence of thermal annealing on microstructures of zinc oxide films deposited by RF magnetron sputtering. Jpn J Appl Phys. 2007; 46: 3319.

27. Husna J, Aliyu MM, Islam MA, Chelvanathan P, Hamzah NR, Hossain MS, et al. Influence of annealing temperature on the properties of $\mathrm{ZnO}$ thin films grown by sputtering. Energy Procedia. 2012; 25: 55-61.

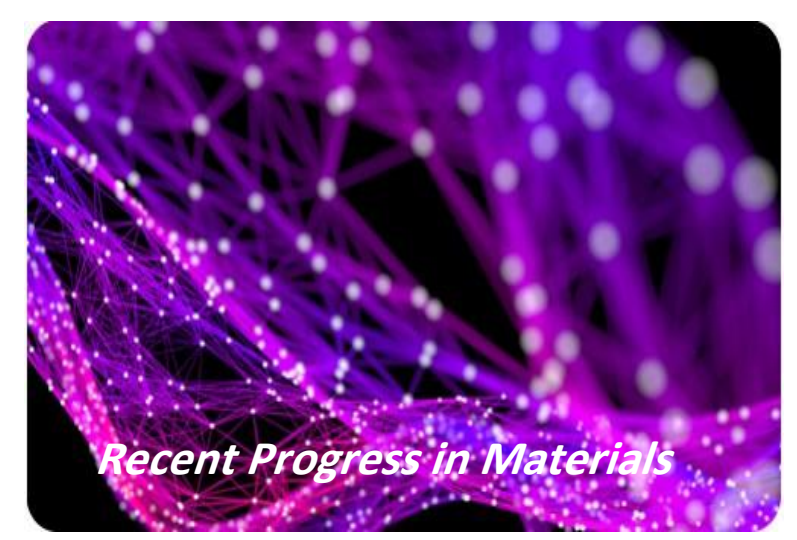

Enjoy Recent Progress in Materials by:

1. Submitting a manuscript

2. Joining in volunteer reviewer bank

3. Joining Editorial Board

4. Guest editing a special issue

For more details, please visit:

http://www.lidsen.com/journals/rpm 